\title{
DESENVOLVIMENTO DE CALÇADO PERSONALIZADO PARA UMA MULHER COM HEMIPARESIA
}

\section{CUSTOMIZED FOOTWEAR DEVELOPMENT FOR A WOMAN WITH HEMIPARESIA}

\author{
Flávio Cardoso Ventura ${ }^{1}$, M.Sc. \\ Rosangela Monteiro dos Santos ${ }^{2}$, M.Sc. \\ Franciene Hernandes ${ }^{3}$, Esp. \\ João Eduardo Guarnetti dos Santos ${ }^{4}$, D.Sc. \\ Marizilda Menezes ${ }^{5}$, D.Sc.
}

(1) Tecnologia em Gestão da Produção Industrial - Faculdade de Tecnologia (FATEC-Jahu)

e-mail: flavio.ventura01@fatec.sp.gov.br

(2) Tecnologia em Gestão da Produção Industrial - Faculdade de Tecnologia (FATEC-Jahu) e-mail: rosangela.santos4@fatec.sp.gov.br

(3) Tecnologia em Gestão da Produção Industrial - Faculdade de Tecnologia (FATEC-Jahu) e-mail: franciene.hernandes@fatec.sp.gov.br

(4) Programa de Pós graduação em Design - Universidade Estadual Paulista "Júlio de Mesquita

Filho" (UNESP-Bauru)

e-mail:guarneti@feb.unesp.br

(5) Programa de Pós graduação em Design - Universidade Estadual Paulista "Júlio de Mesquita

Filho" (UNESP-Bauru)

e-mail: zilmenezes@uol.com.br

Palavras-chave: calçado personalizado, ergonomia, hemiplegia.

As pessoas com hemiparesia (paralisia parcial em um lado do corpo) apresentam alterações no equilíbrio corporal e deformidades no pé, reforçando a necessidade do calçado ser adequado ergonomicamente para promover segurança e bem-estar. O objetivo desta pesquisa foi desenvolver um calçado personalizado para uma mulher com hemiparesia. Participou uma mulher com 35 anos de idade, paciente da APAE-Jaú. Foi realizado uma análise anatômica podal, da baropodometria e postural. A fôrma e a modelagem foram fabricados de maneira artesanal. A confecção do calçado foi adequada as características da usuária, respeitou os aspectos anatômicos, antropométricos e biomecânicos e inclusive, a usuária participou da seleção do modelo desenvolvido. Os calçados são ferramentas protéticas poderosas no sentido de ampliar os valores simbólicos de nossos corpos, reforçam identidades pessoais ou coletivas. 


\section{$16^{\circ}$ \\ ERGODESIGN USIHC CINAHPA}

$16^{\circ}$ Ergodesign - Congresso Internacional de Ergonomia e Usabilidade de Interfaces Humano Tecnológica: Produto, Informações Ambientes Construídos e Transporte

$16^{\circ}$ USIHC - Congresso Internacional de Ergonomia e Usabilidade de Interfaces Humano Computador

CINAHPA | 2017 - Congresso Internacional de Ambientes Hipermídia para Aprendizagem.

Keywords: custom footwear, ergonomics, hemiplegia.

People with hemiparesis (partial paralysis on one side of the body) have changes in the body balance and deformities in the foot, reinforcing the need for shoes to be ergonomically adequate to promote safety and wellbeing. The objective of this research was to develop a personalized footwear for a woman with hemiparesis. A 35year-old female patient from APAE-Jaú participated. An analysis was performed on foot, baropodometry and postural. The molding and molding were handcrafted. Shoemaking was adequate for the characteristics of the wearer, respecting the anatomical, anthropometric and biomechanical aspects. In addition, the user participated in the selection of the model developed. Footwear is powerful prosthetic tools in the sense of expanding the symbolic values of our bodies, reinforcing personal or collective identities.

\section{Introdução}

O calçado é um produto que tem como função mecânica proteger os pés ao entrar em contato com terrenos irregulares, texturas diferentes, variações de temperatura e movimentações durante as atividades, de maneira a proporcionar segurança. Alguns valores são atribuídos ao calçado, baseando-se nos aspectos estéticos e simbólicos que favorecem a auto realização e a estima das pessoas. As pessoas com deficiência física possuem as mesmas necessidades, no entanto, devido as alterações anatômicas e biomecânicas no organismo decorrentes da lesão neurológica, se faz necessários algumas adaptações na fôrma e modelagem do produto para que seu uso seja adequado.

Todas as pessoas com deformidades podais merecem especial atenção para a confecção do calçado. A hemiplegia é um dos tipos de deficiência física mais comuns que é causado por doenças vasculares, crônicas e metabólicas.

Os hemiplégicos apresentam alterações motoras em um lado do corpo, assim um pé (direito ou esquerdo) sofre alterações anatômicas prejudicando a coordenação dos movimentos.

O desenvolvimento de calçados com os fatores anatômicos, antropométricos, biomecânicos adequados e o planejamento da modelagem com designs atuais, contribui para uma locomoção com maior segurança e eficiência, além de interferir no desejo de uso do calçado por hemiplégicos.
O calçado é um produto que exerce influência sobre as funções do pé, e deve ser desenvolvido de acordo com as características anatômicas, antropométricas e biomecânicas. O design do calçado deve fazer a proteção dos pés, favorecer a locomoção e o bem-estar, mas as pessoas com deficiência física encontram dificuldades para adquirir calçados adequados e consideram um fator de exclusão social (LIPI, et al., 2013).

O calçado mostra o reflexo dos valores pessoais e preocupações socioculturais. Assim, o calçado é uma ferramenta para ampliar valores do nosso corpo e está extremamente relacionada com a personalidade do usuário com ou sem deficiência física (RONCHOLETA,2011).

Considerando o exposto, existe a necessidade de investimentos na área de calçados para pessoas com deficiência física.

\subsection{Objetivos}

Os objetivos desta pesquisa foram avaliar a distribuição do peso corporal sobre os pés, desenvolver uma fôrma podal e um calçado personalizado para uma mulher hemiparética.

\section{Referencial teórico}

\subsection{Desenvolvimento de calçados}

O calçado é um produto que faz interface com o pé humano, portanto, seu desenvolvimento deve ser 


\section{$16^{\circ}$ \\ ERGODESIGN USIHC CINAHPA}

baseado a partir de parâmetros anatômicos, antropométricos e biomecânicos das extremidades inferiores. Além destes três aspectos, o design do modelo contribui bastante para a completa satisfação do usuário.

Para a confecção adequada de um calçado é necessário desenvolver uma fôrma podal a partir dos parâmetros ergonômicos.

A fôrma do calçado é a réplica do pé humano. De acordo com Ventura et al. (2011) ela auxilia no dimensionamento das peças que compõem o calçado, serve de base para montagem e acabamento do calçado e determina o formato do calçado.

Para o desenvolvimento da fôrma correta é imprescindível a realização da antropometria (medidas dos pés como comprimento, largura e circunferências das articulações). No entanto, as medidas precisam ser analisadas juntamente com a anatomia. Algumas investigações neste sentido foram realizadas por pesquisadores (CHAMBERS et al, 2011; MENIN, et al., 2009; MANFIO, 1995; LACERDA, et al. 1984). De acordo com Chambers et al. (2011) a idade, a obesidade e o gênero podem ter um impacto significativo na antropometria principalmente nas pessoas com 65 anos ou mais.

Ventura et al. (2011) explana a possibilidade de uma pessoa ter a circunferência idêntica a de outra pessoa, porém, ter o formato diferente, portanto, apesar das medidas serem iguais, um pé terá um calce melhor que outro. O critério para aprovação de uma fôrma deve ser o calce (relação entre anatomia e antropometria), e não somente medidas antropométricas.

De acordo com os autores supracitados uma fôrma de calçados tem a função de proporcionar a conformação e o alinhamento dos materiais, servindo de base para o dimensionamento e montagem das peças do mesmo. Segundo Schimidt (2007) para oferecer um calce adequado, todos os modelos de calçado devem respeitar alguns pontos importantes. Estes fundamentos, orientações são $16^{\circ}$ Ergodesign - Congresso Internacional de Ergonomia e Usabilidade de Interfaces Humano Tecnológica: Produto, Informações Ambientes Construídos e Transporte

$16^{\circ}$ USIHC - Congresso Internacional de Ergonomia e Usabilidade de Interfaces Humano Computador

CINAHPA | 2017 - Congresso Internacional de Ambientes Hipermídia para Aprendizagem.

apresentados através de uma metodologia denominada Linhas Básicas. O desenvolvimento da fôrma é imprescindível para o planejamento e a confecção dos demais elementos do calçado.

Para que todos esses elementos do calçado sejam adequados ao seu respectivo usuário é bom relacionar o modelo a ser desenvolvido com o formato dos pés e com a distribuição de pressão. A distribuição do peso do corpo e da ação da gravidade sobre o pé ocorre em três regiões: retropé (região posterior do pé), mediopé (região intermediária do pé) e antepé (região anterior do pé). A maneira e a quantidade de pressão que será distribuída nessas regiões durante a caminhada está estritamente relacionado a composição anatômica determinadas por fatores internos do organismo (estruturas óssea, articular, muscular, vascular e neuronal) e externos (calçados utilizados).

As maiores dificuldades no desenvolvimento de fôrmas para pessoas com deficiência física é a impossibilidade de definir padrões de fôrmas devido as discrepâncias anatômicas e antropométricas dos pés.

\subsection{Hemiplegia e alterações nos pés}

A hemiplegia é um dos tipos de deficiência física mais comuns que é causado por doenças vasculares, crônicas e metabólicas, como: a hipertensão arterial, diabetes mellitus e colesterol alto. Nas últimas quatro décadas, a incidência do acidente vascular cerebral (AVC) teve um aumento maior que $100 \%$ em países em desenvolvimento. Estudos epidemiológicos realizados na América do Sul revelaram uma incidência de 35 a 183 casos de AVC por mil habitantes e cerca de $60 \%$ dos acometidos ficam com sequelas motoras como a hemiplegia (CONFORTO; FERREIRA, 2009).

De acordo com O'Sullivan e Schmitz (1993) os hemiplégicos apresentam alterações motoras em um lado do corpo. As pessoas com hemiplegia têm a tendência em manter-se em uma posição de assimetria postural, com distribuição de peso menor sobre o lado afetado, e consequentemente transferência de peso corporal para o lado oposto. Essa assimetria e a dificuldade em suportar o peso 


\section{$16^{\circ}$ \\ ERGODESIGN USIHC CINAHPA}

$16^{\circ}$ Ergodesign - Congresso Internacional de Ergonomia e Usabilidade de Interfaces Humano Tecnológica: Produto, Informações Ambientes Construídos e Transporte

$16^{\circ}$ USIHC - Congresso Internacional de Ergonomia e Usabilidade de Interfaces Humano Computador

CINAHPA | 2017 - Congresso Internacional de Ambientes Hipermídia para Aprendizagem. no lado afetado interferem na capacidade de manter o controle postural, impedindo a orientação e estabilidade para realizar movimentos com o tronco e membros (CESÁRIO, 2006).

Na hemiplegia o pé (direito ou esquerdo) sofre alterações anatômicas prejudicando a coordenação dos movimentos dos pés e consequentemente, influencia toda a maneira de locomoção, dificultando o equilíbrio corporal. A deformidade podal que se encontra em hemiplégicos é o pé equino varo - pé flexionado para baixo e rodado/pé caído (CESÁRIO, 2006).

A deformidade do pé parético proporciona um desequilíbrio da pressão plantar elevado, representando um déficit na propulsão do solo podendo resultar em quedas. A queda é um dos fatores de maior preocupação, pois aumenta a debilidade além de interferir na auto segurança do indivíduo. De acordo com Freitas (2010) a incidência de quedas em hemiplégicos é maior do que em idosos.

Outro motivo que reforça a necessidade de calçados específicos para tal população. Um calçado adequado que os auxilie a compensar o déficit na propulsão do solo pode auxiliar na correção da deformidade podal interferindo positivamente no controle dos movimentos das extremidades inferiores e consequentemente, nos demais movimentos compensatórios anormais do membro inferior

Diante dessas limitações diversas organizações têm se preocupado com as questões sobre inclusão social e qualidade de vida. Todas as pessoas com deformidades podais merecem especial atenção para a confecção do calçado.

Lipi, et al. (2013) avaliaram mulheres com hemiplegia que faziam tratamento de reabilitação física sobre os aspectos considerados importantes no calçado. Verificou-se, que as participantes consideram diversos aspectos relacionados a moda, mas não encontram opções. A maioria não tem facilidade para adquirir os calçados desejáveis e as que conseguem comprar, encontram calçados muitas vezes masculinos, sem as características que almejam além da dificuldade pelo uso da órtese no membro inferior, pois a órtese exige que elas encontrem calçados com a numeração diferenciada para cada pé, ou seja, precisam comprar dois pares de calçados idênticos com numerações diferentes para calçar cada pé, a órtese promove percepção diferenciada, além de geralmente ser pesada e aquecerem excessivamente o pé.

Roncholetta (2011) constatou que as mulheres com deficiência destacam as seguintes características em calçado: os sapatos devem ser fáceis de calçar e descalçar, e fáceis de limpar; confeccionados em materiais macios, que permitam a transpiração, e que suas costuras não as machuquem. Devem também proporcionar segurança, isto é, os calçados devem estar firmes em seus pés, bem presos pelo cabedal, seus saltos devem proporcionar estabilidade ao marchar com sola antiderrapante, não provocando a sensação que podem virar o pé, e, por último, seria agradável poder sentir o chão, acrescentam. Elas destacaram como características sensuais e femininas é aquele calçado que faz com que a usuária se sinta confiante, incluída em relação ao meio social, isto é, que lhe proporcione benefícios emocionais, prazer social e psicológico, conforme o contexto da situação.

\section{Metodologia}

Foi realizada uma pesquisa tecnológica sobre desenvolvimento de calçado para uma pessoa com deficiência física. Foi selecionada uma mulher com hemiparesia, 35 anos de idade, $160 \mathrm{~cm}$ de altura, 53 kilogramas, que utiliza órtese para o tornozelo e pé e que realiza tratamento fisioterapêutico em uma instituição de reabilitação neurológica. Antes da coleta dos dados a APAE-Jaú autorizou a realização da pesquisa com sua paciente e a mesma assinou o Termo de Consentimento Livre e Esclarecido de acordo com o Comitê de ética. A usuária esteve envolvida em todas as etapas do projeto e as decisões foram de acordo com as suas preferências, ou seja, ela participou do processo da elaboração do modelo, da seleção dos materiais e da cor. 


\section{$16^{\circ}$ \\ ERGODESIGN USIHC CINAHPA}

Para a análise de pressão plantar foi utilizado o baropodômeto que contêm o programa footwork e as seguintes características: 2704 captadores calibrados, frequência de $150 \mathrm{~Hz}$, conversão analógica de 16 bits, pressão máxima por captor $100 \mathrm{~N} / \mathrm{cm}^{2}$, conexão do PC via USB e as dimensões da plataforma de $575 \times 450 \times 25 \mathrm{~mm}$.

A coleta dos dados sobre pressão plantar foi feita com a paciente na posição em pé de frente para uma parede branca sem estímulos visuais, pisando na plataforma de pressão e permanecendo na posição estática por 20 segundos. Antes da coleta dos dados a paciente foi instruída a permanecer na mesma posição sem movimentar o corpo. $\mathrm{O}$ sistema gravou o procedimento por 20 segundos e forneceu os dados de pressão em Kilopascais (Kpa). A paciente realizou o procedimento três vezes para aumentar a confiabilidade da avaliação.

A análise dos resultados foi a partir de dados quantitativos: pressão máxima, pressão média, centro da força de pressão, superfície e divisão de massa dos pés direito e esquerdo.

O desenvolvimento da fôrma podal (replica dos pés) foi realizada em 2 fases (molde negativo e positivo). O molde negativo foi realizado com alginato e água e o molde positivo foi realizado através do preenchimento do molde negativo com material de polímero.

A confecção do calçado foi realizada com materiais do Laboratório da Fatec Jahu e o desenvolvimento da modelagem e montagem do calçado foi realizado com a colaboração dos pesquisadores da Fatec Jahu e Senai de Jaú.

Para a confecção da parte inferior do calçado foi analisado a baropodometria e a análise postural para alinhar o nível de quadril do lado direito com o lado esquerdo e para a parte superior do calçado (cabedal) foram consideradas as medidas e formato da órtese para caber na sandália.

A modelagem do calçado foi manual e a montagem do calçado foi realizado na própria usuária. Além de considerar a opinião da usuária, os aspectos anatômicos e biomecânicos foram avaliados para $16^{\circ}$ Ergodesign - Congresso Internacional de Ergonomia e Usabilidade de Interfaces Humano Tecnológica: Produto, Informações Ambientes Construídos e Transporte

$16^{\circ}$ USIHC - Congresso Internacional de Ergonomia e Usabilidade de Interfaces Humano Computador

CINAHPA | 2017 - Congresso Internacional de Ambientes Hipermídia para Aprendizagem.

propiciar a seleção do modelo mais adequado as suas caraterísticas.

\section{Resultados e Discussão}

Na primeira análise da baropodometria apresentado na Figura 1, observa-se que a paciente distribui o peso do corpo mais na região posterior com 54\% em relação a anterior com $46 \%$. Percebese, que os picos de pressão representados pela letra $\mathrm{x}$ na cor preta ocorrem na mesma região no pé direito e esquerdo, no calcanhar. No pé direito, a paciente sobrecarrega mais o retropé com 26,97\% do peso corporal que o antepé com 14,03\%. No pé esquerdo, a região mais sobrecarregada é o antepé com $32,19 \%$ e o retropé com $26,82 \%$. Ressalta-se, que o pé esquerdo, contralateral a lesão é o pé que sofre maior descarga de peso.

\section{Figura 1. Primeira análise da baropodometria}

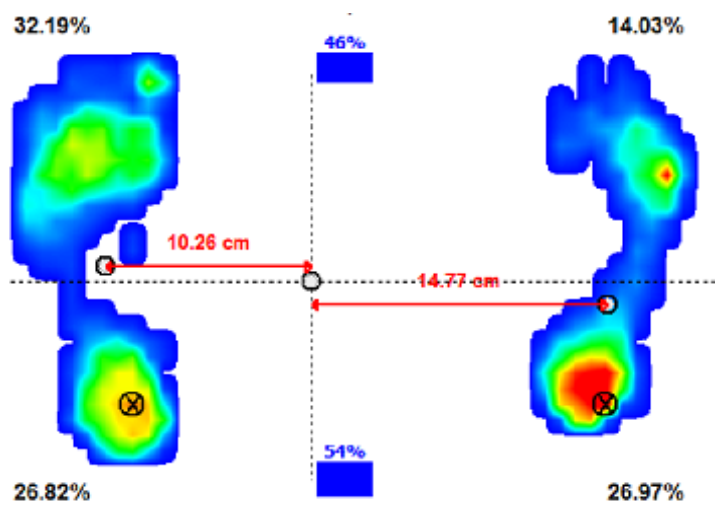

Fonte: Autores (2016)

Na segunda baropodometria, a Participante distribuiu $52 \%$ do peso do corpo na região anterior e $48 \%$ na região posterior. O pico de pressão representado pela letra $\mathrm{x}$ na cor preta encontra-se no antepé no lado direito e no hálux (dedão do pé) no lado esquerdo. No pé direito $14,97 \%$ do peso é distribuído no antepé e $27,23 \%$ no retropé. No lado esquerdo, 36,98\% é distribuído no antepé e $20,82 \%$ no retropé. $O$ pé mais sobrecarregado continua sendo o pé esquerdo (oposto ao pé com deficiência) - Figura 2. 


\section{$16^{\circ}$ \\ ERGODESIGN USIHC CINAHPA}

$16^{\circ}$ Ergodesign - Congresso Internacional de Ergonomia e Usabilidade de Interfaces Humano Tecnológica: Produto, Informações Ambientes Construídos e Transporte

$16^{\circ}$ USIHC - Congresso Internacional de Ergonomia e Usabilidade de Interfaces Humano Computador

CINAHPA | 2017 - Congresso Internacional de Ambientes Hipermídia para Aprendizagem.
Figura 2 - Segunda análise da baropodometria.

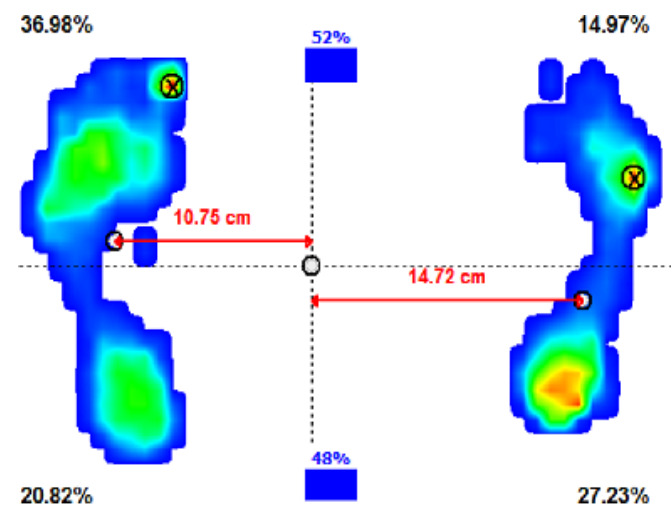

Fonte: Autores (2016)

Na terceira análise, os dados são semelhantes à segunda análise. O peso do corpo está distribuído igualmente na região anterior e posterior do corpo. A região de pico de pressão encontra-se no antepé direito e no hálux no pé esquerdo. No pé direito, o antepé recebe $15,93 \%$ do peso e no retropé

$26,77 \%$. No pé esquerdo, o antepé recebe $33,74 \%$ do peso e o retropé $23,57 \%$. O pé esquerdo

continua sendo o mais sobrecarregado- Figura 3.

Figura 3 - Terceira análise da baropodometria.

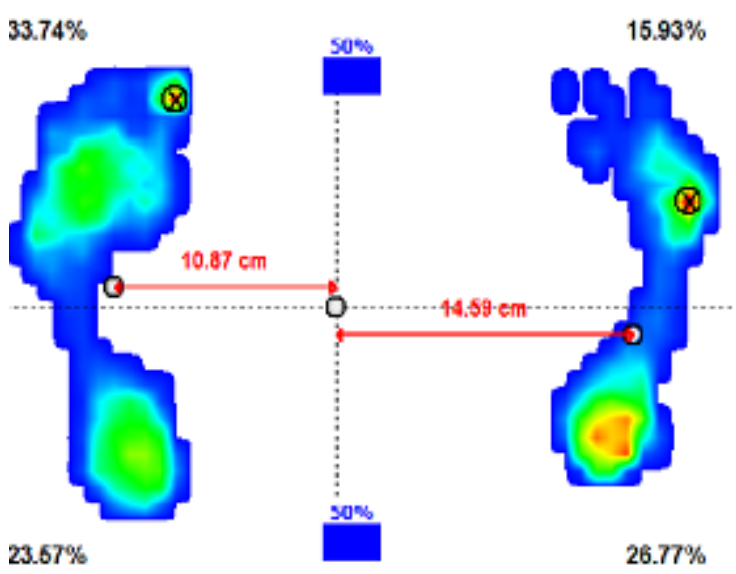

Fonte: Autores (2016)

Para melhor compreensão da distribuição de pressão em cada região a Tabela 1 mostra a pressão média, pressão máxima dos dois membros de cada avaliação.
Pode-se notar que as três avaliações apresentaram dados semelhantes para a pressão média, sendo a maior no pé esquerdo (lado oposto a lesão) aproximadamente 69,99 Kpa. As divergências ocorreram apenas para a pressão máxima no lado esquerdo, variando entre 99,18 e $323 \mathrm{KPA}$. A variação é significativa, no entanto, é importante salientar que o baropodômetro capta também as oscilações corporais e que os dados de cada análise representam um segundo dentro dos 20 segundos que foram gravados, ou seja, uma oscilação mínima, por exemplo causada por um padrão respiratório diferente é suficiente para alterar o resultado. Os resultados de maior descarga do peso corporal no lado corporal não acometido corroboram com diversas pesquisas (CESÁRIO, et al, 2003; SCHUSTER, 2008).

\section{Tabela 1. Dados sobre pressões média e máxima}

\begin{tabular}{ccccc} 
Análises & $\begin{array}{c}\text { Pressão } \\
\text { MédiaD }\end{array}$ & $\begin{array}{l}\text { Pressão } \\
\text { MédiaE }\end{array}$ & $\begin{array}{l}\text { Pressão } \\
\text { MáximaD }\end{array}$ & $\begin{array}{l}\text { Pressão } \\
\text { MáximaE }\end{array}$ \\
\hline Análise1 & $67,9 \mathrm{Kpa}$ & $64,93 \mathrm{Kpa}$ & $337 \mathrm{Kpa}$ & $302 \mathrm{Kpa}$ \\
Análise2 & $65,8 \mathrm{Kpa}$ & $64,99 \mathrm{Kpa}$ & $309 \mathrm{Kpa}$ & $323 \mathrm{Kpa}$ \\
Análise3 & $66 \mathrm{Kpa}$ & $69,99 \mathrm{Kpa}$ & $307,08 \mathrm{Kpa}$ & $99,18 \mathrm{Kpa}$
\end{tabular}

Fonte: Autores (2016)

A Tabela 2 mostra a divisão de massa da região lateral, anterior e posterior dos pés dos dois membros em cada avaliação. Nas três análises observa-se que a paciente distribui peso do corpo mais para o lado esquerdo (de 56 a $59 \%$ do peso corporal) e 41 a $44 \%$ para o lado direito. $\mathrm{Na}$ divisão anterior e posterior de cada pé, vê-se que o pé direito a distribuição de pressão ocorre mais no calcanhar (66\% a $70 \%)$ e no pé esquerdo no antepé $(55 \%$ a $64 \%)$.
Realização:
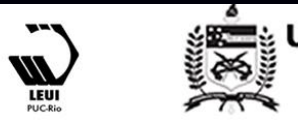


\section{$16^{\circ}$ \\ ERGODESIGN USIHC CINAHPA}

$16^{\circ}$ Ergodesign - Congresso Internacional de Ergonomia e Usabilidade de Interfaces Humano Tecnológica: Produto, Informações Ambientes Construídos e Transporte

$16^{\circ}$ USIHC - Congresso Internacional de Ergonomia e Usabilidade de Interfaces Humano Computador

CINAHPA | 2017 - Congresso Internacional de Ambientes Hipermídia para Aprendizagem.
Tabela 2 - Dados sobre divisão de massa

\begin{tabular}{cccccc}
$\begin{array}{c}\text { Divisão } \\
\text { Lateral } \\
\text { Direita }\end{array}$ & $\begin{array}{c}\text { Divisão } \\
\text { Lateral } \\
\text { Esquerda }\end{array}$ & $\begin{array}{c}\text { Divisão } \\
\text { anterior } \\
\text { Esquerda }\end{array}$ & $\begin{array}{c}\text { Divisão } \\
\text { posterior } \\
\text { Esquerda }\end{array}$ & $\begin{array}{c}\text { Divisão } \\
\text { Anterior } \\
\text { Direita }\end{array}$ & $\begin{array}{c}\text { Divisão } \\
\text { Posterior } \\
\text { Direita }\end{array}$ \\
\hline $44 \%$ & $56 \%$ & $56 \%$ & $44 \%$ & $30 \%$ & $70 \%$ \\
$42 \%$ & $58 \%$ & $64 \%$ & $36 \%$ & $35 \%$ & $65 \%$ \\
$41 \%$ & $59 \%$ & $55 \%$ & $45 \%$ & $34 \%$ & $66 \%$
\end{tabular}

De acordo com os dados apresentados da baropodometria, a palmilha e o solado do pé esquerdo devem promover na região do antepé o amortecimento igual ou maior que o do calcanhar, visto que a região de maior absorção de impacto durante o andar se localiza no antepé. O lado direito apresenta absorção de impacto no calcanhar, porém, a descarga de peso é menor no lado direito (lado da lesão). A baropodometria fornece dados sobre a descarga de peso, mas é necessário a análise clínica para prescrição da palmilha, analisando os segmentos corporais, que são descritos no tópico da fabricação da palmilha.

Para avaliar o alinhamento do quadril (equilíbrio entre o lado direito e esquerdo), a participante ficou na postura em pé e foi marcado com uma caneta o posicionamento da crista ilíaca (ossos pontudos da bacia). A Figura 4 mostra, o alinhamento do quadril com a participante utilizando a órtese. Verifica-se, que a órtese diminui a diferença de altura entre o lado direito e esquerdo, no entanto, o lado esquerdo continua mais alto.
Figura 4 - Altura do quadril da participante com o uso da órtese

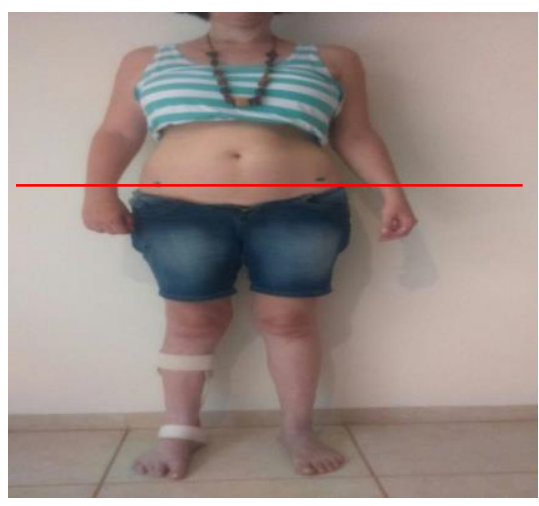

Fonte: Autores (2016)

A palmilha e o solado foram confeccionados com material de Etil Venil Acetato (E.V.A.) na espessura de $10 \mathrm{~mm}$ para o pé esquerdo e de 15 $\mathrm{mm}$ no pé direito com a finalidade de corrigir a diferença de altura, respeitando o formato da planta do pé. A participante provou a palmilha e o solado, fazendo uso da órtese antes de dar continuidade no processo de confecção do calçado.

Foi selecionado o modelo de sandália burkin. A paciente utiliza órtese, e esse formato se adequa bem ao formato da órtese e proporciona amortecimento de impacto adequado, segurança, flexibilidade e conforto.

O material da confecção foi um couro vazado na cor azul (preferência da participante).

Para a realização da modelagem, as fôrmas dos pés foram envolvidas completamente por fita crepe. Em seguida foi desenhada o modelo sob a fôrma. Na modelagem tradicional, o procedimento é realizado apenas em um pé e no corte do material é realizado o espelhamento (inverte o lado) obtendose o par. Neste caso, como as medidas nos dois pés eram diferentes, devido a órtese, foi realizada uma modelagem para cada pé. A fabricação do calçado passou pelas etapas de confecção (corte do material de couro de acordo com as peças cortadas da modelagem, acabamento das peças dobradas, coladas um forro, pespontados (costurados) e refilados (tirado o excesso do material do forro). A montagem do calçado foi realizada no pé da
Realização:

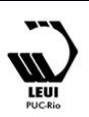




\section{$16^{\circ}$ \\ ERGODESIGN USIHC CINAHPA}

participante, conforme Figura 5.

\section{Figura 5 - Montagem do calçado}

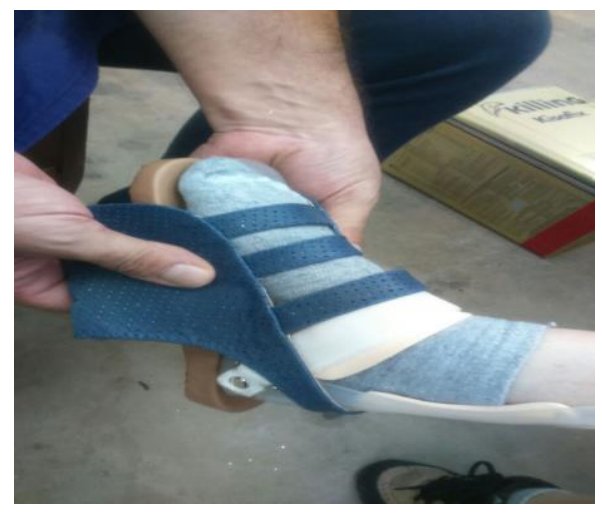

Fonte: Autores (2016)

A confecção do calçado com acabamentos pode ser visualizada através da Figura 6.

Figura 6 - Produto acabado.

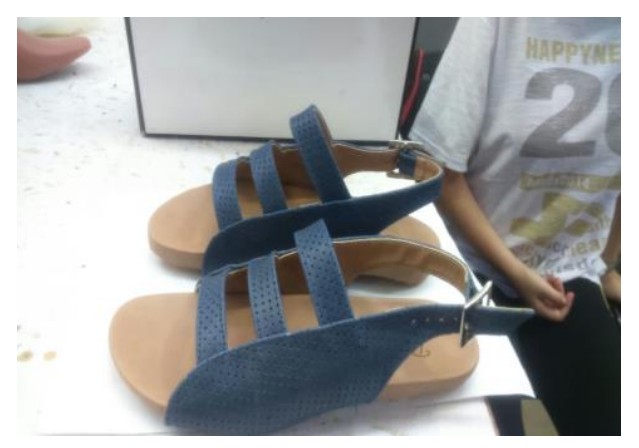

A Figura 7 ilustra a paciente usando a sandália e o alinhamento do quadril, percebe-se que a altura da crista ilíaca, mantem-se equilibrada com o uso do calçado. $16^{\circ}$ Ergodesign - Congresso Internacional de Ergonomia e Usabilidade de Interfaces Humano Tecnológica: Produto, Informações Ambientes Construídos e Transporte

$16^{\circ}$ USIHC - Congresso Internacional de Ergonomia e Usabilidade de Interfaces Humano Computador

CINAHPA | 2017 - Congresso Internacional de Ambientes Hipermídia para Aprendizagem.

\section{nivelamento do quadril}

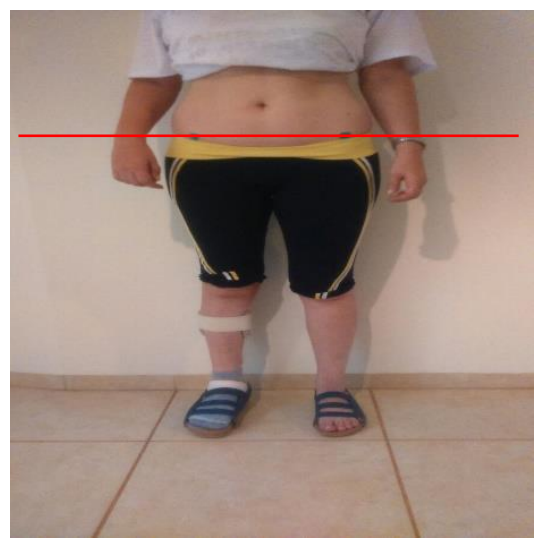

Fonte: Autores (2016)

\section{Considerações finais}

O presente estudo teve a finalidade de desenvolver um calçado personalizado para uma mulher com hemiplegia a partir dos parâmetros ergonômicos Foi confeccionada uma sandália do modelo burkin, com material de couro vazado na cor azul. A seleção do modelo foi realizada a partir das preferências da participante e da análise antropométrica, anatômica considerando a utilização da órtese, postural favorecendo o nivelamento dos quadris e biomecânica através da baropodometria para beneficiar a marcha.

O modelo selecionado foi o que proporciona conforto, segurança e a própria mulher pode opinar no modelo e na cor da sandália, fatores que favorecem o aumento da satisfação com o produto. A sandália foi confeccionada de maneira que se adeque as medidas e favoreça o equilíbrio simétrico do corpo. A paciente apresenta um padrão flexor de joelho, favorecendo a diminuição do lado lesado, mesmo com a utilização da órtese. A sandália confeccionada teve a finalidade de proporcionar o alinhamento e o equilíbrio.

A usuária relatou estar satisfeita com o aspecto anatômico e com o design da sandália.

Acredita-se que todos os calçados desenvolvidos visando a melhor adequação ao pé, aos processos de locomoção e a satisfação com uso, agregam 


\section{$16^{\circ}$ \\ ERGODESIGN USIHC CINAHPA}

$16^{\circ}$ Ergodesign - Congresso Internacional de Ergonomia e Usabilidade de Interfaces Humano Tecnológica: Produto, Informações Ambientes Construídos e Transporte

$16^{\circ}$ USIHC - Congresso Internacional de Ergonomia e Usabilidade de Interfaces Humano Computador

CINAHPA | 2017 - Congresso Internacional de Ambientes Hipermídia para Aprendizagem. mais valor ao produto. Os calçados para pessoas com deficiência física, pode-se supor, que o valor é potencializado considerando as inúmeras dificuldades que as mulheres encontram para adquirir qualquer tipo de calçado, sendo praticamente impossível adquirir um calçado com características de sua preferência, seja de tamanho, modelo, cor entre outros.

Pesquisas como esta, contribuem para a generalização dos procedimentos realizados na construção da fôrma, na elaboração do modelo e da confecção. Á partir do estudo realizado, diversas pesquisas podem ser realizadas. Torna-se interessante, investigar a diferença entre diversos tipos de modelo, outros tipos de ajustes no calçado, outros tipos de deficiência física e a diferença de processos de confecção manual e digitalizado.

\section{BIBLIOGRAFIA}

CONFORTO, A.B.; FERREIRA, J.R.

Neuroestimulação e reabilitação motora no Acidente Vascuar Cerebral. Revista eletrônica de jornalismo científico,v.1, 2009.

CHAMBERS, A.J.; SUKITS, A.L; McCRORY, J.L; CHAM, R. Differences in geriatric anthropometric data between DXA-based subjectspecific estimates and non-age-specific traditional regression models. J Appl Biomech. v.27, n.3, 2011.

CESÁRIO, C.M.M.; PENASSO, P.; OLIVEIRA, A.P.R. Impacto da disfunção motora na qualidade de vida em pacientes com Acidente Vascular Encefálico. Rev. Neurociênc. v. 14, n. 1, São Paulo, 2006.

\section{LACERDA, D. F. Medição Antropométrica dos}

Pés. [Dissertação de Mestrado]94f.. Programa de Pós graduação em engenharia da Universidade Federal do Rio de Janeiro- COPPE/UFRJ, Rio de Janeiro, 1984.
LIPI, L. A. ; VALENTIM, R. A.; SANTOS, R.M. Análise da acessibilidade de portadores de necessidades especiais para a compra de calçados. IN: III Encontro Científico do GEPro, FatecJahu, 2013.

\section{MANFIO, E. F. Estudo de Parâmetro}

Antropométricos e Biomecânicos do Pé

Humano Orientado para a Fabricação de Calçados segundo Critérios de Conforto, Saúde

e Segurança. [Dissertação de Mestrado].112p.

Programa de Pós graduação em Educação física da Universidade Federal de Santa Maria, UFSM, Sata Maria, 1995.

O'SULLIVAN, S. B.; SCHMITZ, T. J.

Fisioterapia: avaliação e tratamento. 2. ed. São Paulo: Manole, 1993.

RONCOLETTA, M.R. O desejo de mulheres portadoras de deficiencia física no design de calçados. IN: I Encontro Nacional de Pesquisa em Moda, Goiânia, Universidade Federal de Goiás, 2011

RONCOLETTA, M. Calçados sensuais para mulheres excepcionais: uma reflexão sobre design de calçados para mulheres portadoras de restrições físicas. Dissertação (Mestrado em Design) - Programa de Pós-Graduação Mestrado em Design da Universidade Anhembi Morumbi UAM, São Paulo, 2008.

SCHIMIDT, M. R. Modelagem Técnica de Calçados . Senai - Serviço Nacional de Aprendizagem Industrial . Porto Alegre, 2007.

SCHUSTER, A. L. Análise da pressão plantar em pacientes com acidente vascular encefálico. Rev. Neurociências, v.16, n.3,p. 170-183, 2008

VENTURA, F.C.; PASCHOARELLI, L.C.; SILVA, J.C.P. Inovação tecnológica e o desenvolvimento de fôrmas no polo calçadista jauense...ANAIS In $\mathbf{1 1}^{\circ}$ ERGODESIGN USIHC, Manaus, 2011. 
$16^{\circ}$

ERGODESIGN USIHC CINAHPA $16^{\circ}$ Ergodesign - Congresso Internacional de Ergonomia e Usabilidade de Interfaces Humano Tecnológica: Produto, Informações Ambientes Construídos e Transporte

$16^{\circ}$ USIHC - Congresso Internacional de Ergonomia e Usabilidade de Interfaces Humano Computador

CINAHPA | 2017 - Congresso Internacional de Ambientes Hipermídia para Aprendizagem.

\section{Agradecimentos}

APAE-Jaú

Fatec-JAHU

CPRJI -FATEC 